Retraction

\title{
Retracted: Targeting Mitochondria as Therapeutic Strategy for Metabolic Disorders
}

\section{The Scientific World Journal}

Received 22 September 2019; Accepted 22 September 2019; Published 17 October 2019

Copyright ( $) 2019$ The Scientific World Journal. This is an open access article distributed under the Creative Commons Attribution License, which permits unrestricted use, distribution, and reproduction in any medium, provided the original work is properly cited.

The Scientific World Journal has retracted the article titled "Targeting Mitochondria as Therapeutic Strategy for Metabolic Disorders" [1]. The article was found to contain a substantial amount of material without citation, from the following source:

"Mitochondrial Dysfunction in Diabetes: From Molecular Mechanisms to Functional Significance and Therapeutic Opportunities," by William I. Sivitz and Mark A. Yorek published in Antioxidants \& Redox Signaling, vol. 12, no. 4, 537-577 pages, DOI: 10.1089/ars.2009.2531, https://www. liebertpub.com/doi/full/10.1089/ars.2009.2531 [2].

\section{References}

[1] D. Sorriento, A. Valeria Pascale, R. Finelli et al., "Targeting mitochondria as therapeutic strategy for metabolic disorders," The Scientific World Journal, vol. 2014, Article ID 604685, 9 pages, 2014.

[2] W. I. Sivitz and M. A. Yorek, "Mitochondrial dysfunction in diabetes: from molecular mechanisms to functional significance and therapeutic opportunities," Antioxidants \& Redox Signaling, vol. 12, no. 4, pp. 537-577, 2010. 